\title{
L-Glutamine Administration Reduces Oxidized Glutathione and MAP Kinase Signaling in Dystrophic Muscle of $m d x$ Mice
}

\author{
ELISE MOK, BRUNO CONSTANTIN, FRÉDÉRIC FAVREAU, NATHALIE NEVEUX, CHRISTOPHE MAGAUD, \\ ADRIANA DELWAIL, AND RÉGIS HANKARD
}

\begin{abstract}
UMR CNRS 6187 [B.C., C.M.], Institut de Physiologie et Biologie Cellulaires; EA 3813 [E.M., R.H.] Laboratoire Adaptation Physiologique aux Activités Physiques, Faculté de Médecine et de Pharmacie [F.F.]; EA3806 [A.D.], Laboratoire Cytokines et Inflammation, Université de Poitiers, Poitiers 86000, France; Inserm ERM 324 [F.F.], Ischémie-reperfusion en transplantation rénale, Poitiers 86000, France; Service de Biochimie [F.F.], Centre d'Investigation Clinique [R.H.], Pédiatrie Multidisciplinaire - Nutrition de l'Enfant [R.H.], CHU de Poitiers, Poitiers 86000, France; and Biochimie A [N.N.], Hôpital Hôtel Dieu - Assistance Publique-Hôpitaux de Paris, Paris 75181, France
\end{abstract}

\begin{abstract}
To determine whether glutamine (Gln) reduces the ratio of oxidized to total glutathione (GSSG/GSH) and extracellular signal-regulated kinase (ERK1/2) activation in dystrophic muscle. Four-week old $m d x$ mice, an animal model for Duchenne muscular dystrophy and control (C57BL/10) received daily intraperitoneal injections of $\mathrm{L}-\mathrm{Gln}(500 \mathrm{mg} / \mathrm{kg} / \mathrm{d})$ or $0.9 \% \mathrm{NaCl}$ for $3 \mathrm{~d}$. GSH and GSSG concentrations in gastrocnemius were measured using a standard enzymatic recycling procedure. Free amino acid concentrations in gastrocnemius were determined by ion exchange chromatography. Phosphorylated protein levels of ERK1/2 in quadriceps were examined using Western Blot. L-Gln decreased GSSG and GSSG/GSH (an indicator of oxidative stress). This was associated with decreased ERK1/2 phosphorylation. Muscle free Gln, glutamate (Glu), and the sum $(\mathrm{Gln}+\mathrm{Glu})$ were higher in $m d x$ versus $\mathrm{C} 57 \mathrm{BL} / 10$, at the basal level. Exogenous Gln decreased muscle free Glu and Gln + Glu in $m d x$ only, whereas Gln was not affected. In conclusion, exogenous Gln reduces GSSG/GSH and ERK1/2 activation in dystrophic skeletal muscle of young $m d x$ mice, which is associated with decreased muscle free Glu and Gln + Glu. This antioxidant protective mechanism provides a molecular basis for Gln's antiproteolytic effect in Duchenne muscular dystrophy children. (Pediatr Res 63: 268-273, 2008)
\end{abstract}

$\mathrm{D}$ uchenne muscular dystrophy (DMD) is a progressive muscle-wasting disease resulting from the absence of dystrophin. Dysregulation of calcium homeostasis, increased oxidative stress, and proteolysis are among potential pathogenic mechanisms implicated in DMD muscle-wasting, downstream of the genetic defect (1-4). Oxidative stress could contribute to muscle-wasting by regulating specific cell signaling pathways leading to increased proteolysis (5). We have shown that glutamine (Gln) supplementation decreases whole

Received May 15, 2007; accepted October 15, 2007.

Correspondence: Régis Hankard, M.D., Ph.D., Pédiatrie Multidisciplinaire-Nutrition de l'Enfant, Centre Hospitalier Universitaire de Poitiers, 2 rue de la Milétrie 86021 Poitiers Cedex, France; e-mail: r.hankard@chu-poitiers.fr

Supported by a grant from Institut National de la Santé et de la Recherche Médicale \#33104700 (RAF 01005) (to R.H.) and the Association Française Contre les Myopathies (to R.H.), and by Les Fonds de la Recherche en Santé Québec (PhD Fellowship to E.M.) and Le Prix de Nutrition de la Fédération Association Nationale pour les Traitements A Domicile, les Innovations et la Recherche awarded by La Société Francophone de Nutrition Entérale et Parentérale (to E.M.). body protein breakdown in DMD children $(6,7)$. However, the molecular basis for glutamine's antiproteolytic effect remains to be elucidated.

Antioxidants can improve muscle health by protecting cells from oxidative stress and reducing muscle necrosis in $m d x$ mice (an animal model of DMD) (8-11). Several studies have shown that oxidative stress elicited by various stimuli is associated with activation of the extracellular signal-regulated kinase (ERK1/2) mitogen activated protein kinase (MAPK) pathway $(12,13)$, which could participate in pathways influencing protein breakdown $(5,14,15)$. In turn, ERK1/2 activation can be inhibited by antioxidants (10). Furthermore, dystrophic muscle of DMD patients (3) and $m d x$ mice $(1,2)$ undergo increased oxidative stress. And increased ERK1/2 activation was reported in skeletal muscle of $m d x$ mice $(10,16)$, which was further increased in response to mechanical stress (4).

Therapeutic strategies that target downstream events in the progression of dystrophic pathology can yield worthwhile functional improvement in DMD (17). Gln supplementation provides a protective effect against oxidative stress in various tissues $(18,19)$. Thus, the primary objective of the present study is to test whether exogenous Gln reduces the ratio of GSSG/GSH [the major regulator of the cellular redox potential and a widely used indicator of oxidative stress (20)] in skeletal muscle of $m d x$ mice. And since oxidative stress mediates activation of MAPK (ERK1/2) and NF- $\kappa$ B transactivation (13), we determined the effect of Gln on this pathway. Also because skeletal muscle plays a central role in Gln metabolism (as the main producer and exporter of Gln) and whole body Gln exchange is decreased in DMD (21), we examined the effect of exogenous Gln on muscle-free amino acid concentrations.

Abbreviations: C57, C57BL/10; DMD, Duchenne muscular dystrophy; ERK1/2, extracellular signal-regulated kinase1/2; Gln, glutamine; Glu, glutamate; GSH, total glutathione; GSSG, oxidized glutathione; IкB $\boldsymbol{\alpha}$, I-kappaB-alpha; MAPK, mitogen activated protein kinase; NaCl, sodium chloride; $\mathbf{N F}-\boldsymbol{\kappa} \mathbf{B}$, Nuclear factor-kappaB; TNF- $\boldsymbol{\alpha}$, Tumour necrosis factor-alpha 


\section{METHODS}

Animals and L-glutamine administration. Four-week-old dystrophin deficient $(m d x, n=8)$ and control (C57BL/10, $n=8)$ mice were housed on a 12:12 h light:dark cycle and received ad libitum water and standard rodent chow. Mice were separated into four groups: (1) $0.9 \% \mathrm{NaCl}-\mathrm{C} 57 \mathrm{BL} / 10$ (NaCl-C57), (2) L-glutamine-C57BL/10 (GLN-C57), (3) $0.9 \% \mathrm{NaCl}-m d x$ (NaCl-MDX), and (4) L-glutamine- $m d x$ (GLN-MDX). Mice received daily intraperitoneal (i.p.) injections for $3 \mathrm{~d}$ of a $3 \%$ solution $(500 \mathrm{mg} / \mathrm{kg}$ body weight) of L-glutamine dissolved in $0.9 \% \mathrm{NaCl}$ or $0.9 \% \mathrm{NaCl}$ only. The body weight of each mouse was measured daily during the 3-d treatment period. Mice were killed by cervical dislocation on the third day of posttreatment. All procedures and animal treatment followed the guidelines established by the French council on animal care.

The quadriceps and gastrocnemius muscles were rapidly dissected. Both quadriceps muscles and one gastrocnemius muscle were immediately frozen in liquid nitrogen and stored at $-80^{\circ} \mathrm{C}$ until Western blot analyses (or ELISA) and determination of free amino acids, respectively. The other gastrocnemius muscle was rinsed in phosphate buffered saline containing $0.16 \mathrm{mg} / \mathrm{mL}$ heparin, to remove any red blood cells and clots. Gastrocnemius muscle was homogenized in ice cold MES buffer $(0.2 \mathrm{M} 2$ - $(N$-morpholino $)$ ethanesulphonic acid, $0.05 \mathrm{M}$ phosphate, $1 \mathrm{mM}$ EDTA $\mathrm{pH}$ 6), and centrifuged at $10,000 \mathrm{~g}$ for $15 \mathrm{~min}$ at $4^{\circ} \mathrm{C}$. An aliquot of the supernatant was used for total protein determination with the bicinchoninic acid assay kit (Sigma-Aldrich, St. Quentin Fallavier, France). The remaining supernatant was deproteinated by mixing with an equal volume of metaphosphoric acid reagent (SigmaAldrich) and centrifuging at $2000 \mathrm{~g}$ for $2 \mathrm{~min}$. The supernatant was stored at $-80^{\circ} \mathrm{C}$ until glutathione assay.

Western blot analyses and determination of TNF- $\alpha$ concentrations. Frozen quadriceps muscle was homogenized in cold lysis buffer $(50 \mathrm{mM}$ Tris $\mathrm{HCl} \mathrm{pH} \mathrm{7.4,} 150 \mathrm{mM} \mathrm{NaCl}, 5 \mathrm{mM}$ EDTA, $0.05 \%$ Nonidet P-40, $1 \%$ DOC, $1 \%$ Triton X-100, 0.1\% SDS, $1 \%$ Protease Inhibitor Cocktail) on ice. The supernatants obtained after samples were centrifuged at 15,000 $\mathrm{g}$ for $20 \mathrm{~min}$ at $4^{\circ} \mathrm{C}$ were used for subsequent Western blot analyses or stored at $-80^{\circ} \mathrm{C}$ before determination of TNF- $\alpha$ concentrations via ELISA according to the manufacturer's instructions (R\&D Systems, Lille, France). Total protein was determined with DC protein assay kit (Bio-Rad Laboratories, Marnes-laCoquette, France). Fifty micrograms of protein from each sample was mixed with loading buffer $(187.5 \mathrm{mM}$ Tris $\mathrm{HCl} \mathrm{pH}$ 6.8, 6\% SDS, $30 \%$ glycerol, $0.03 \%$ Bromophenol blue, $5 \%$ alpha monothioglycerol), denatured for $5 \mathrm{~min}$ at $100^{\circ} \mathrm{C}$ and then separated by $12.5 \%$ SDS-PAGE. Proteins were then transferred to a nitrocellulose membrane. The blot was blocked in Trisbuffered saline (TBS) with $0.1 \%$ Tween-20 (TBS/T) containing 5\% nonfat dry milk (wt/vol) washed in TBS/T $(1 \times$ TBS, $0.1 \%$ Tween-20) and then incubated in primary antibody diluted in 5\% bovine serum albumin in TBS/T overnight at $4^{\circ} \mathrm{C}$. Membranes were then washed in TBS/T and incubated with horseradish peroxidase (HRP)-conjugated secondary antibody. After washing in TBS/T, protein detection was performed using LumiGLO chemiluminescent substrate (Upstate cell signaling solutions, Euromedex, Mundolsheim, France) and exposure to x-ray film. Antibodies and the conditions used in these measurements were as follows: rabbit anti-phospho-p44/42 MAPK (Thr202/Tyr204) (the activated form of ERK1/2), 1:1000 (Cell Signaling Technology, St. Quentin Yvelines, France), rabbit anti-phospho-I $\kappa \mathrm{B} \alpha$ (Ser32), 1:1000 (Cell Signaling Technology), and anti-rabbit secondary antibody conjugated to HRP, 1:2000 (Cell Signaling Technology). Troponin T (Sigma-Aldrich) (molecular weight of approximately $38 \mathrm{kD}$ ) was used to control for equal loading in each lane of the gel. The molecular weights of the immunodetected proteins were verified by using the biotinylated protein ladder (Cell Signaling Technology). Protein band intensity was assessed by scanning densitometry. Arbitrary values were expressed as a percentage of values for untreated $\mathrm{C} 57 \mathrm{BL} / 10$ muscle (NaCl-C57), the arbitrary value as $100 \%$. TNF- $\alpha$ concentrations were expressed as picograms per milligram of protein.

Glutathione assay. Total glutathione (GSH) and oxidized glutathione (GSSG) within the gastrocnemius muscle tissue were measured with the glutathione assay kit (Cayman Chemical, Spi-Bio, Montigny Le Bretonneux, France) as described by the manufacturer's instructions. In brief, the deproteinated sample was used to determine GSH content via a standard enzymatic recycling procedure. To determine the GSSG content, an aliquot of the deproteinated supernatant was mixed with 2-vinyl-pyridine (Sigma-Aldrich) and triethanolamine (Sigma-Aldrich) and then assayed.

Determination of muscle free amino acid concentrations. Frozen gastrocnemius muscle was homogenized with ice-cold trichloroacetic acid (TCA $10 \% /$ EDTA $0.5 \mathrm{mM})$ containing norvaline $(200 \mu \mathrm{M})$ as an internal standard and stored on ice for $10 \mathrm{~min}$. The supernatants obtained after samples were centrifuged at $2000 \mathrm{~g}$ for $10 \mathrm{~min}$ at $4^{\circ} \mathrm{C}$, and were flash-frozen in liquid nitrogen and immediately stored at $-80^{\circ} \mathrm{C}$ for subsequent determination of free amino acid concentrations. The pellet was stored at $4{ }^{\circ} \mathrm{C}$ and used for subsequent total protein determination with DC protein assay kit (Bio-Rad Laboratories). Free amino acids in the supernatant were determined by ion exchange chromatography on an AminoTac JLC/500-V analyser (JEOL Cróissy-sur-Seine, France) (22).

Statistical analysis. The effects of treatment (L-Gln vs. $0.9 \% \mathrm{NaCl}$ ) and mouse strain $(m d x v s$. C57BL/10) on variables were determined using 2-way ANOVA. Body weight data were analyzed by repeated ANOVA measures with treatment and mouse strain as between subject factors and time as the within subject factor. Post hoc comparisons were carried out by using Fisher's PLSD test. A value for $p<0.05$ was considered statistically significant. All values are expressed as mean \pm SEM.

\section{RESULTS}

Body weight during $\mathrm{L}_{-} \mathrm{Gln}$ or $0.9 \% \mathrm{NaCl}$ administration. There was a significant effect of mouse strain (C57BL/10 vs. $m d x)$ on body weight $(p<0.0001)$ (Fig. 1). Specifically, body weight was significantly lower in $m d x$ mice versus agematched wild-type C57BL/10 controls, regardless of whether they were treated with $0.9 \% \mathrm{NaCl}(\mathrm{NaCl}-\mathrm{MDX}: 10.5 \pm 0.5 \mathrm{~g}$ vs. NaCl-C57: $17.0 \pm 0.3 \mathrm{~g} ; p<0.0001$ ) or L-Gln (GLNMDX: $10.4 \pm 0.3 \mathrm{~g} v s$. GLN-C57: $16.0 \pm 0.7 \mathrm{~g} ; p<0.0001)$. We found no significant effect of treatment (L-Gln vs. 0.9\% $\mathrm{NaCl}$ ) on body weight for C57BL/10 and $m d x$ mice. During the 3-d experimental period, a significant increase in body weight was observed in all four groups $(p<0.0001)$.

L-Gln decreases GSSG and GSSG/GSH ratio in $m d x$ skeletal muscle. A significant effect of treatment (L-Gln vs. $0.9 \% \mathrm{NaCl})$ was observed for GSSG $(p<0.05)$ and the ratio of GSSG/GSH $(p<0.05)$ (Fig. $2 B$ and $C$, respectively). After glutamine treatment, there was a significant decrease in GSSG $(p<0.05)$ and GSSG/GSH ratio $(p<0.05)$ in $m d x$ and C57BL/10 mice. There were no differences in GSH concentration between the groups (Fig. 2A).

Downregulation of phospho-ERK1/2 (p44/42 MAPK) in mdx skeletal muscle following $L_{-}-G l n$. There was a significant effect of treatment on the expression of the activated form of ERK1/2 (phospho-ERK1/2) $(p<0.01)$ (Fig. 3). L-Gln administration significantly decreased the level of phospho-ERK1/2

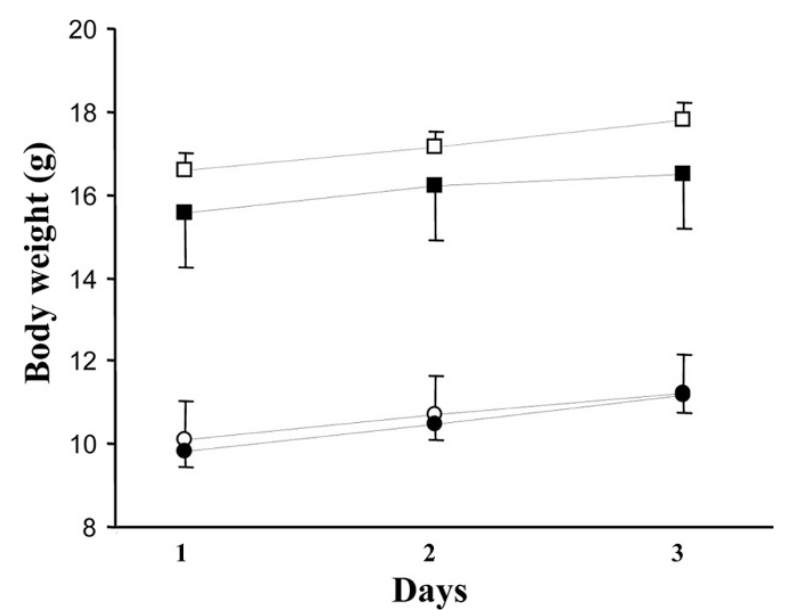

Figure 1. Mean \pm SEM body weight changes in 4-wk-old C57BL/10 $(n=$ 8 ) and $m d x$ mice $(n=8)$ during daily i.p. L-Gln or $0.9 \% \mathrm{NaCl}$ administration over 3 d. $p<0.0001$ for $m d x$ vs. C57BL/10. Open squares: NaCl-C57 $=0.9 \%$ NaCl-C57BL/10; solid squares: GLN-C57 = L-glutamine-C57BL/10; open circles: $\mathrm{NaCl}-\mathrm{MDX}=0.9 \% \mathrm{NaCl}-m d x$; solid circles: GLN-MDX $=\mathrm{L}-$ glutamine- $m d x$. 

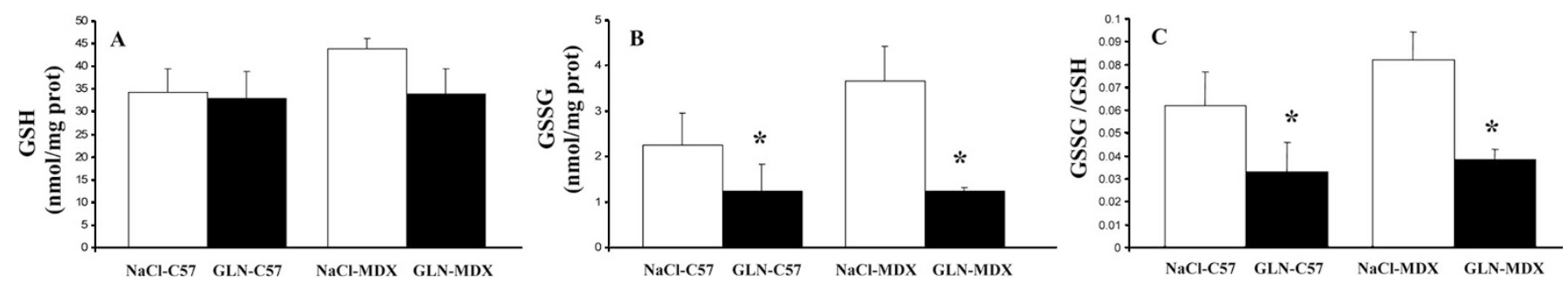

Figure 2. Measurements of $(A)$ total glutathione (GSH), $(B)$ oxidized glutathione (GSSG), and $(C)$ GSSG/GSH ratio in gastrocnemius muscle of 4-wk-old C57BL/10 $(n=8)$ and $m d x$ mice $(n=8)$ after 3 d i.p. L-Gln or $0.9 \% \mathrm{NaCl}$ administration. Means \pm SEM $* p<0.05$ for GLN vs. NaCl. NaCl-C57 $=0.9 \%$ NaCl-C57BL/10, GLN-C57 = L-glutamine-C57BL/10, NaCl-MDX $=0.9 \%$ NaCl-mdx, GLN-MDX = L-glutamine- $m d x$.
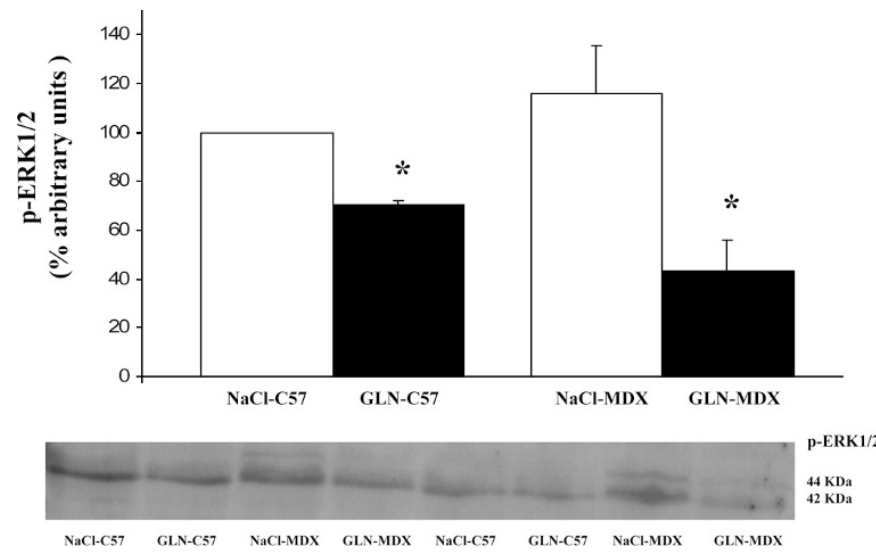

Figure 3. Semi-quantitative analyses and representative Western blot of phospho-ERK1/2 (p44/42) in quadriceps muscle of 4-wk-old C57BL/10 $(n=$ $8)$ and $m d x$ mice $(n=8)$ after 3 d i.p. L-Gln or $0.9 \% \mathrm{NaCl}$ administration. Means \pm SEM $* p<0.01$ for GLN $v s$. NaCl. Immuno-blotting for troponin $\mathrm{T}$ served as a control for protein loading. NaCl-C57 $=0.9 \% \mathrm{NaCl}-\mathrm{C} 57 \mathrm{BL} / 10$, GLN-C57 = L-glutamine-C57BL/10, NaCl-MDX $=0.9 \%$ NaCl- $m d x$, GLNMDX $=$ L-glutamine- $m d x$.

(p44/42) in $m d x$ and C57BL/10 mice $(p<0.01)$. The magnitude of the decrease was twofold greater in $m d x$ compared with control mice ( $63 \%$ vs. $29 \%$, respectively). Interestingly, the p44 band ( $44 \mathrm{kD}$ protein) was almost absent in the control C57BL/10, regardless of treatment $(0.9 \% \mathrm{NaCl}$ and $\mathrm{L}-\mathrm{Gln})$. Similarly, the p44 band almost completely disappeared in $m d x$ mice treated with L-Gln.

$T N F-\alpha$ concentrations and $N F-\kappa B$ signaling in skeletal muscle. Figure 4 shows the effects of mouse strain (C57BL/10 vs. $m d x$ ) and treatment (L-Gln vs. $0.9 \% \mathrm{NaCl}$ ) on TNF- $\alpha$ concentrations and phospho- $\mathrm{I} \kappa \mathrm{B} \alpha$ expression in quadriceps muscle. Although there were no significant effects on TNF- $\alpha$ concentrations, Gln treatment seemed to offset the increase in muscle TNF- $\alpha$ concentrations in $m d x$ mice $(p=0.055)$ (Fig. $4 A$ ). We were able to clearly detect the phosphorylated form of $\mathrm{I} \kappa \mathrm{B} \alpha$ in muscle of $\mathrm{C} 57 \mathrm{BL} / 10$ and $m d x$ mice (Fig. $4 B$ ). However, I $\kappa \mathrm{B} \alpha$ phosphorylation was not increased in $m d x$ muscle. Gln treatment did not affect $\mathrm{I} \kappa \mathrm{B} \alpha$ phosphorylation.

Skeletal muscle free amino acid concentrations. Figure 5 shows the concentration of free amino acids in gastrocnemius muscle. There was a significant effect of mouse strain (C57BL/10 vs. $m d x$ ) on intramuscular free Gln concentrations $(p<0.05)$ (Fig. 5A). Muscle Gln concentrations were significantly higher in $m d x$ versus C57/BL10 mice $(p<0.05)$. A significant interaction (mouse strain $\times$ treatment) was observed for the concentrations of glutamate (Glu) $(p<0.05)$
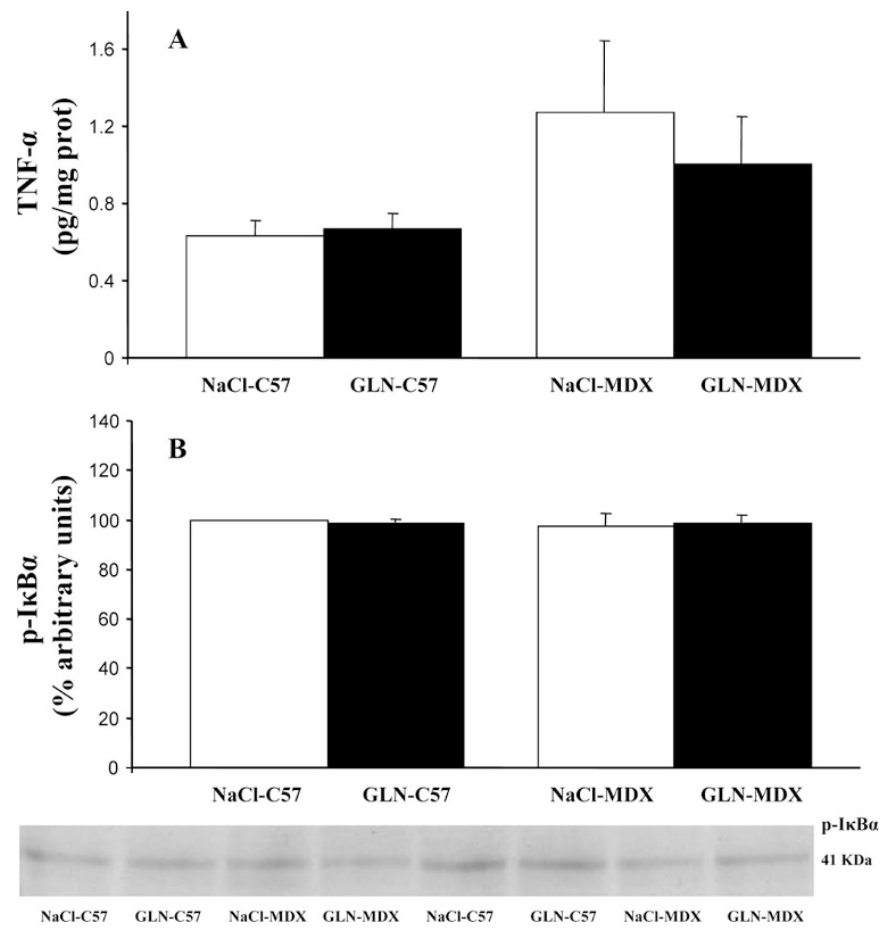

Figure 4. (A) TNF- $\alpha$ protein concentrations determined by ELISA in quadriceps muscle of 4-wk-old C57BL/10 $(n=8)$ and $m d x$ mice $(n=8)$ after $3 \mathrm{~d}$ i.p. L-Gln or $0.9 \% \mathrm{NaCl}$ administration. Means $\pm \operatorname{SEM} p=0.055$ for $m d x$ vs C57BL/10. (B) Semi-quantitative analyses (Means \pm SEM) and representative Western blot of phospho-I $\kappa \mathrm{B} \alpha$ in quadriceps muscle of 4-wk-old C57BL/10 $(n=8)$ and $m d x$ mice $(n=8)$ after 3 d i.p. L-Gln or $0.9 \% \mathrm{NaCl}$ administration. NaCl-C57 $=0.9 \%$ NaCl-C57BL/10, GLN-C57 $=$ L-glutamine-C57BL/10, NaCl-MDX $=0.9 \%$ NaCl- $m d x$, GLN-MDX $=\mathrm{L}_{-}$ glutamine- $m d x$.

and the sum of Gln + Glu $(p<0.05)$ (Fig. $5 B$ and $C$, respectively). Basal concentrations of Glu and Gln + Glu were significantly greater in $m d x$ versus control muscle ( $\mathrm{NaCl}-$ $m d x$ vs. NaCl-C57, $p<0.001)$. Gln treatment significantly decreased free intramuscular Glu and Gln + Glu in $m d x$ mice only $(p<0.05)$. Muscle Gln concentration alone was not affected by Gln treatment. The sum of all amino acids and the essential amino acids did not significantly differ between groups (Fig. $5 D$ and $E$, respectively).

\section{DISCUSSION}

Acute daily IP Gln administration over 3 d decreased GSSG/GSH in skeletal muscle of young $m d x$ mice. Free Glu and the sum of Gln + Glu decreased in $m d x$ muscle, whereas muscle free Gln was not affected by exogenous Gln. The 


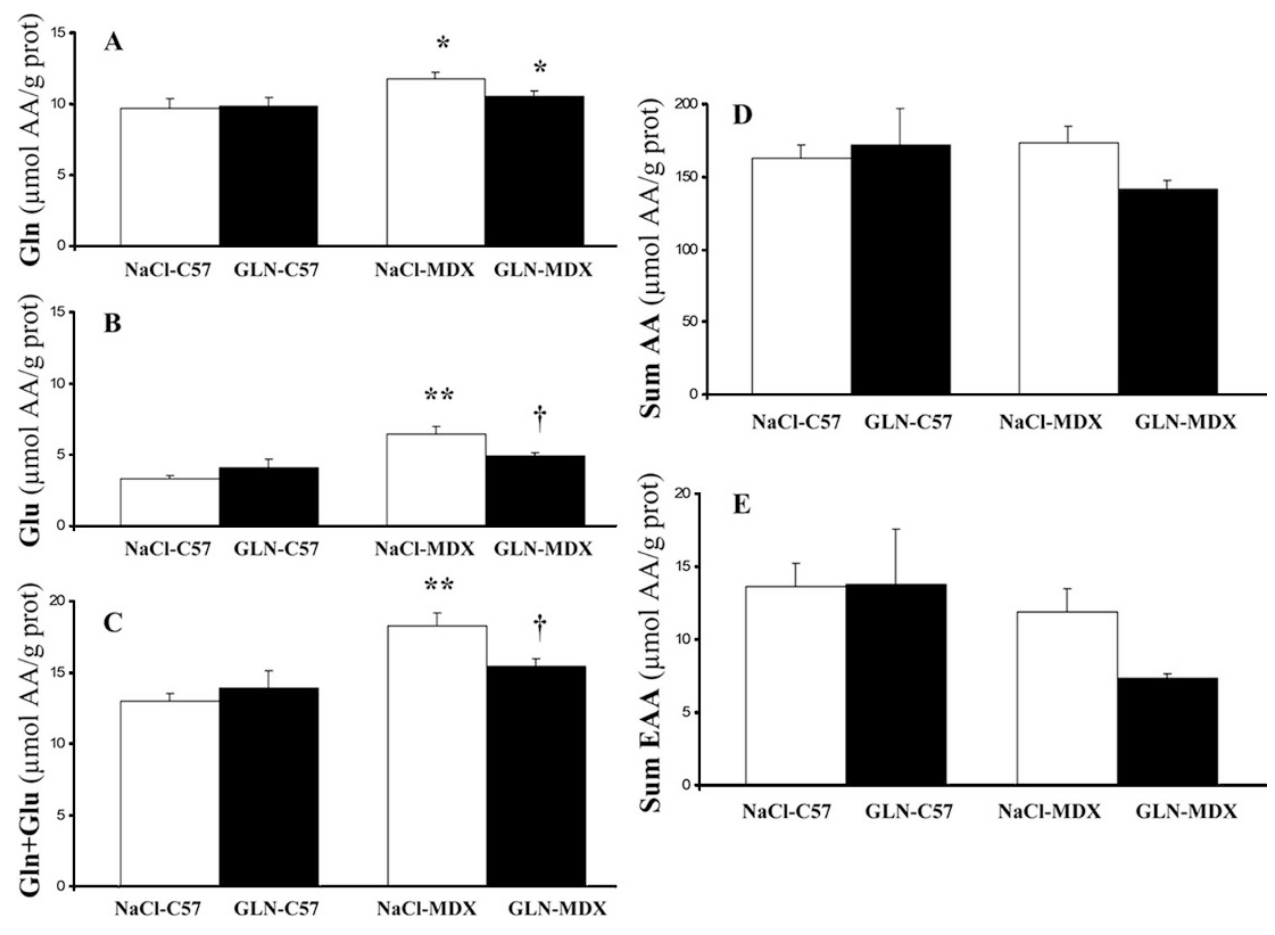

Figure 5. Mean \pm SEM concentrations of free intracellular $(A)$ glutamine $(\mathrm{Gln}),(B)$ glutamate (Glu) and the sum of $(C)$ Gln + Glu, $(D)$ amino acids (AA), and $(E)$ essential amino acids (EAA) in gastrocnemius muscle ( $\mu \mathrm{mol} \mathrm{AA/g}$ protein) of 4-wk-old C57BL/10 $(n=8)$ and $m d x$ mice $(n=8)$ after 3 d i.p. L-Gln or $0.9 \% \mathrm{NaCl}$ administration. $* p<0.05$ for $m d x v s$. C57BL/10, $* * p<0.001$ for NaCl-mdx vs. NaCl-C57, $\dagger p<0.05$ for GLN- $m d x$ vs. NaCl- $m d x$. $\mathrm{AA}=$ amino acids, EAA $=$ essential amino acids, NaCl-C57 $=0.9 \% \mathrm{NaCl}-$ C57BL/10, GLN-C57 = L-glutamineC57BL $/ 10, \mathrm{NaCl}-\mathrm{MDX}=0.9 \% \mathrm{NaCl}-$ $m d x$, GLN-MDX $=$ L-glutamine- $m d x$.

decrease in GSSG/GSH was associated with a reduction in MAPK (ERK1/2) phosphorylation. The antioxidant mechanism may explain our previous findings in DMD children demonstrating decreased whole body protein degradation after $5 \mathrm{~h}$ and $10 \mathrm{~d}$ Gln supplementation $(6,7)$. This study is novel in describing a molecular basis for Gln's antiproteolytic effect in dystrophic muscle.

Here, we observed that $m d x$ mice (under basal conditions) showed increased muscle-free Gln and Glu concentrations. This could result from either an increase in proteolysis or Gln de novo synthesis in $m d x$ muscle, both of which contribute to the muscle-free intracellular Gln pool. This is consistent with increased muscle Gln production during catabolic stress, as demonstrated by enhanced Gln synthetase expression in skeletal muscle after exogenous glucocorticoids (23). In postabsorptive humans, muscle normally releases Gln, while other tissues extract Gln, whereas Glu is taken up by muscle (24). Moreover, it has been reported in critically ill patients that Glu was the only amino acid that showed net uptake across the leg muscle and Glu net uptake correlated with Gln net release (25). Hence, the increased Gln needs by other tissue in DMD pathology may result in increased muscle protein degradation or Glu uptake by muscle to provide precursors for increased Gln de novo synthesis (via Gln synthetase) for subsequent export to other tissue, all at the expense of muscle proteins. In turn after exogenous Gln, we observed a decrease in intracellular Glu and the sum of Gln + Glu in $m d x$ muscle, whereas muscle-free Gln was not affected. This may result from an inhibition of muscle protein degradation or a reduction in Glu uptake for Gln de novo synthesis for subsequent export to other tissue, because Gln availability was increased. Likewise, we showed in DMD children that exogenous Gln decreases Gln de novo synthesis (6). Moreover, during the dystrophic process, other tissue may preferentially make use of the provided Gln, leaving skeletal muscle Gln concentration unaltered by exogenous Gln.

The role of oxidative stress in the pathogenesis of DMD is supported by studies showing consistently higher antioxidant enzyme activities and lipid peroxidation products in $m d x$ muscle $(1,2,9,26)$. Furthermore, $m d x$ muscle cells and DMD skin fibroblasts show an increased susceptibility to oxidative damage $(27,28)$, suggesting a role of the glutathione antioxidant system in dystrophic pathology (28). Recently, increased GSSG/GSH was reported in young (prenecrotic) $m d x$ hindlimb muscle, suggesting an abnormal glutathione status in dystrophic muscle under basal conditions and before muscle necrosis (2).

In the present study, Gln supplementation significantly decreased oxidized glutathione (GSSG) and the GSSG/GSH ratio in skeletal muscle. GSH was not affected, which is in keeping with the lack of increase in muscle Gln or Glu concentrations after exogenous Gln [Gln being a precursor of the Glu for GSH synthesis (20)]. The effectiveness of glutathione protection in individual tissue depends on the tissue concentration of glutathione and the capacity of the tissue to import the reduced form of glutathione and to export GSSG (29). During catabolic conditions (e.g., critical illness) a change in the redox status occurs, indicative of an increased muscle GSSG relative to GSH concentration (29). Shifting the GSSG/GSH redox toward the oxidizing state activates specific signaling pathways (20), including those involved in proteolysis. Because the cellular redox status seems to be related to the degree of muscle protein degradation $(30,31)$, this may contribute to the protein catabolism observed in DMD. Exogenous Gln decreased GSSG and GSSG/GSH, and hence could protect against oxidative stress damage (i.e., decrease oxidized/damaged proteins that undergo subsequent degradation). This could then lead to a decrease in muscle necrosis in DMD, 
because increased oxidative stress precedes the onset of muscle necrosis, as shown by induction of expression of genes encoding antioxidant enzymes in prenecrotic $m d x$ muscle (32).

Interestingly, decreased GSSG/GSH after Gln supplementation was associated with decreased MAPK (ERK1/2) activation. Oxidative stress could contribute to muscle wasting by regulating specific cell signaling pathways. First, it is possible that oxidative stress leads to cytosolic calcium overload (33) and subsequent activation of calcium-activated proteases (calpain) in skeletal muscle (5). A second potential link between oxidative stress and muscle proteolysis is the control of caspase 3 activity, because caspase 3 activation pathways can be triggered by reactive oxygen species (5). A third possible mechanism is the redox regulation of the ubiquitinproteasome proteolytic system, because oxidative stress can increase muscle protein breakdown via the $26 \mathrm{~s}$ and 20 s core proteasome, which degrades oxidatively damaged proteins $(34,35)$. Finally, oxidative stress could increase proteolysis by control of MAPK signaling (5). ERK1/2 has been shown to be activated in $m d x$ skeletal muscle at rest $(10,16)$ and in response to mechanical stretch (4). Importantly, ERK1/2, c-Jun $\mathrm{N}$ terminal kinase, and p38 MAPK have all been shown to be activated by oxidative stress in skeletal myoblasts (13). Moreover, ERK1/2 could participate in pathways influencing protein breakdown via the autophagic lysosome pathway (15). Autophagy is the major proteolytic pathway in the cell and the only pathway known to be regulated by plasma amino acids $(14,15)$. Gln may cause its antiproteolytic effect through osmotic swelling (36) involving the MAPK pathway (37). Likewise, amino acids can control autophagic lysosomal protein degradation by inhibiting ERK1/2 phosphorylation (15). We suggest that Gln may decrease oxidative stress and subsequent protein degradation via modulation of the ERK1/2 MAPK signaling pathway.

By inhibiting the shift toward the oxidizing state and subsequent ERK1/2 activation, exogenous Gln may also prevent the inflammatory cascade, associated with the dystrophic process. In support of this, ERK1/2 is implicated in Activator Protein-1 transcriptional activity and NF- $\kappa \mathrm{B}$ transactivation by oxidative stress $(5,13)$. In turn, mechanical-stretch-induced activation of Activator Protein-1 was decreased after pretreatment of $m d x$ muscle fibers with PD98059, an ERK1/2 inhibitor (4). And recent reports in $m d x$ muscle, highlight the implication of oxidative stress/lipid peroxidation via MAPK cascade and NF- $\kappa \mathrm{B}$ activation, in turn triggering an inflammatory cascade that leads to muscle necrosis $(9,10)$. We observed that Gln treatment might offset the increase in $m d x$ muscle TNF- $\alpha$ inflammatory cytokine concentrations (approaching significance). Interestingly, unlike classical NF- $\kappa \mathrm{B}$ activation, we observed that $\mathrm{I} \kappa \mathrm{B} \alpha$ phosphorylation was not increased in $m d x$ muscle. Moreover, Gln treatment did not affect muscle $\mathrm{I} \kappa \mathrm{B} \alpha$ phosphorylation. Thus Gln treatment might offset the increase in proinflammatory cytokine (TNF- $\alpha$ ) concentrations in $m d x$ muscle, without affecting $\mathrm{I} \kappa \mathrm{B}-\alpha$ phosphorylation. Our findings are in line with a recent study showing that $\mathrm{I} \kappa \mathrm{B}-\alpha$ phosphorylation was not associated with the dystrophic phenotype and that pharmacological inhibition of I $\kappa \mathrm{B}$ kinase decreased NF- $\kappa \mathrm{B}$ activity in $m d x$ muscle without affecting I $\kappa \mathrm{B}-\alpha$ phosphorylation or degradation (38). Hence, NF- $\kappa \mathrm{B}$ activation by I $\kappa \mathrm{B}$ kinase may occur independently of classical $\mathrm{I} \kappa \mathrm{B}$ phosphorylation.

Our findings provide important and novel information that integrates the fields of nutrition, molecular biology, and muscle pathophysiology in childhood disease. The antioxidant protective mechanism of Gln has therapeutic implications for slowing disease progression in DMD children, thus improving quality of life. Moreover, therapeutic strategies (e.g., Gln nutritional therapy) to prevent oxidant production/scavenge free radicals could apply to other muscle-wasting pathologies.

Acknowledgment. We are grateful to Dr. C. Cognard and Dr. G. Raymond for providing the laboratory and animal facility where the majority of the work was performed. We thank Dr. N. Bourmeyster for his advice regarding biochemical analysis. We also thank the members of the Laboratoire Cytokines et Inflammation EA 3806, especially Dr. J-C. Lecron for ELISA advice.

\section{REFERENCES}

1. Dudley RW, Danialou G, Govindaraju K, Lands L, Eidelman DE, Petrof BJ 2006 Sarcolemmal damage in dystrophin deficiency is modulated by synergistic interactions between mechanical and oxidative/nitrosative stresses. Am J Pathol 168:12761287; quiz 1404-1405

2. Dudley RW, Khairallah M, Mohammed S, Lands L, Des Rosiers C, Petrof BJ 2006 Dynamic responses of the glutathione system to acute oxidative stress in dystrophic mouse (mdx) muscles. Am J Physiol Regul Integr Comp Physiol 291:R704-R710

3. Haycock JW, MacNeil S, Jones P, Harris JB, Mantle D 1996 Oxidative damage to muscle protein in Duchenne muscular dystrophy. Neuroreport 8:357-361

4. Kumar A, Khandelwal N, Malya R, Reid MB, Boriek AM 2004 Loss of dystrophin causes aberrant mechanotransduction in skeletal muscle fibers. FASEB J 18:102113

5. Powers SK, Kavazis AN, McClung JM 2007 Oxidative stress and disuse muscle atrophy. J Appl Physiol 102:2389-2397

6. Hankard RG, Hammond D, Haymond MW, Darmaun D 1998 Oral glutamine slows down whole body protein breakdown in Duchenne muscular dystrophy. Pediatr Res 43:222-226

7. Mok E, Eleouet-Da Violante C, Daubrosse C, Gottrand F, Rigal O, Fontan JE, Cuisset JM, Guilhot J, Hankard R 2006 Oral glutamine and amino acid supplementation inhibit whole-body protein degradation in children with Duchenne muscular dystrophy. Am J Clin Nutr 83:823-828

8. Buetler TM, Renard M, Offord EA, Schneider H, Ruegg UT 2002 Green tea extract decreases muscle necrosis in mdx mice and protects against reactive oxygen species. Am J Clin Nutr 75:749-753

9. Messina S, Altavilla D, Aguennouz M, Seminara P, Minutoli L, Monici MC, Bitto A, Mazzeo A, Marini H, Squadrito F, Vita G 2006 Lipid Peroxidation Inhibition Blunts Nuclear Factor-\{kappa\}B Activation, Reduces Skeletal Muscle Degeneration, and Enhances Muscle Function in mdx Mice. Am J Pathol 168:918-926

10. Hnia K, Hugon G, Rivier F, Masmoudi A, Mercier J, Mornet D 2007 Modulation of p38 mitogen-activated protein kinase cascade and metalloproteinase activity in diaphragm muscle in response to free radical scavenger administration in dystrophindeficient Mdx mice. Am J Pathol 170:633-643

11. Dorchies OM, Wagner S, Vuadens O, Waldhauser K, Buetler TM, Kucera P, Ruegg UT 2006 Green tea extract and its major polyphenol (-)-epigallocatechin gallate improve muscle function in a mouse model for Duchenne muscular dystrophy. Am J Physiol Cell Physiol 290:C616-C625

12. Park BG, Yoo CI, Kim HT, Kwon CH, Kim YK 2005 Role of mitogen-activated protein kinases in hydrogen peroxide-induced cell death in osteoblastic cells. Toxicology 215:115-125

13. Kefaloyianni E, Gaitanaki C, Beis I 2006 ERK1/2 and p38-MAPK signalling pathways, through MSK1, are involved in NF-kappaB transactivation during oxidative stress in skeletal myoblasts. Cell Signal 18:2238-2251

14. Kadowaki M, Kanazawa T 2003 Amino acids as regulators of proteolysis. J Nutr 133:2052S-2056S

15. Ogier-Denis E, Pattingre S, El Benna J, Codogno P 2000 Erk1/2-dependent phosphorylation of Galpha-interacting protein stimulates its GTPase accelerating activity and autophagy in human colon cancer cells. J Biol Chem 275:39090-39095

16. Barton ER 2006 Impact of sarcoglycan complex on mechanical signal transduction in murine skeletal muscle. Am J Physiol Cell Physiol 290:C411-C419

17. Tidball JG, Wehling-Henricks M 2004 Evolving therapeutic strategies for Duchenne muscular dystrophy: targeting downstream events. Pediatr Res 56:831-841

18. Thomas S, Prabhu R, Balasubramanian KA 2005 Surgical manipulation of the intestine and distant organ damage-protection by oral glutamine supplementation. Surgery 137:48-55 
19. Wischmeyer PE, Jayakar D, Williams U, Singleton KD, Riehm J, Bacha EA, Jeevanandam V, Christians U, Serkova N 2003 Single dose of glutamine enhances myocardial tissue metabolism, glutathione content, and improves myocardial function after ischemia-reperfusion injury. JPEN J Parenter Enteral Nutr 27:396-403

20. Wu G, Fang YZ, Yang S, Lupton JR, Turner ND 2004 Glutathione metabolism and its implications for health. J Nutr 134:489-492

21. Hankard R, Mauras N, Hammond D, Haymond M, Darmaun D 1999 Is glutamine a 'conditionally essential' amino acid in Duchenne muscular dystrophy? Clin Nutr 18:365-369

22. Neveux N, David P, Cynober L 2003 Measurement of amino acid concentration in biological fluids and tissues using ion-exchange chromatography. In: Cynober LA (ed) Metabolic and Therapeutic Aspects of Amino Acids in Clinical Nutrition. CRC Press, Boca Raton, FL, pp 17-28

23. Abcouwer SF, Bode BP, Souba WW 1995 Glucocorticoids regulate rat glutamine synthetase expression in a tissue-specific manner. J Surg Res 59:59-65

24. Darmaun D, Matthews DE, Desjeux JF, Bier DM 1988 Glutamine and Glu nitrogen exchangeable pools in cultured fibroblasts: a stable isotope study. J Cell Physiol 134:143-148

25. Vesali RF, Klaude M, Rooyackers OE, Tjader I, Barle H, Wernerman J 2002 Longitudinal pattern of Gln/Glu balance across the leg in long-stay intensive care unit patients. Clin Nutr 21:505-514

26. Ragusa RJ, Chow CK, Porter JD 1997 Oxidative stress as a potential pathogenic mechanism in an animal model of Duchenne muscular dystrophy. Neuromuscul Disord 7:379-386

27. Disatnik MH, Chamberlain JS, Rando TA 2000 Dystrophin mutations predict cellular susceptibility to oxidative stress. Muscle Nerve 23:784-792

28. Degl'Innocenti D, Rosati F, Iantomasi T, Vincenzini MT, Ramponi G 1999 GSH system in relation to redox state in dystrophic skin fibroblasts. Biochimie 81:10251029
29. Wernerman J, Luo JL, Hammarqvist F 1999 Glutathione status in critically-ill patients: possibility of modulation by antioxidants. Proc Nutr Soc 58:677-680

30. Tischler ME 1980 Is regulation of proteolysis associated with redox-state changes in rat skeletal muscle? Biochem J 192:963-966

31. Fagan JM, Tischler ME 1986 Reduction-oxidation state and protein degradation in skeletal muscle of fasted and refed rats. J Nutr 116:2028-2033

32. Disatnik MH, Dhawan J, Yu Y, Beal MF, Whirl MM, Franco AA, Rando TA 1998 Evidence of oxidative stress in mdx mouse muscle: studies of the pre-necrotic state. J Neurol Sci 161:77-84

33. Kourie JI 1998 Interaction of reactive oxygen species with ion transport mechanisms. Am J Physiol 275:C1-C24

34. Grune T, Merker K, Sandig G, Davies KJ 2003 Selective degradation of oxidatively modified protein substrates by the proteasome. Biochem Biophys Res Commun 305:709-718

35. Li YP, Chen Y, Li AS, Reid MB 2003 Hydrogen peroxide stimulates ubiquitinconjugating activity and expression of genes for specific E2 and E3 proteins in skeletal muscle myotubes. Am J Physiol Cell Physiol 285:C806-C812

36. Low SY, Rennie MJ, Taylor PM 1997 Signaling elements involved in amino acid transport responses to altered muscle cell volume. FASEB J 11:1111-1117

37. Haussinger D, Schliess F, Dombrowski F, Vom Dahl S 1999 Involvement of p38MAPK in the regulation of proteolysis by liver cell hydration. Gastroenterology 116:921-935

38. Acharyya S, Villalta SA, Bakkar N, Bupha-Intr T, Janssen PM, Carathers M, Li ZW, Beg AA, Ghosh S, Sahenk Z, Weinstein M, Gardner KL, Rafael-Fortney JA, Karin M, Tidball JG, Baldwin AS, Guttridge DC 2007 Interplay of IKK/NF-kappaB signaling in macrophages and myofibers promotes muscle degeneration in Duchenne muscular dystrophy. J Clin Invest 117:889-901 